\title{
Antônio Lavareda y Helcimara de Souza Telles (Editores), Como o eleitor escolhe seu prefeito: campanha e voto nas eleições municipais, \\ RIO de JaneIRO, EDITORA FGV, 2011.
}

\author{
Érica Anita Baptista Silva ${ }^{1}$ \\ Paulo Victor Melo ${ }^{2}$
}

El libro Cómo el elector elige a su alcalde, coordinado por los politólogos Antônio Lavareda y Helcimara Telles, constituye toda una referencia para los estudios electorales en Brasil. Las investigaciones sobre el ámbito municipal fueron interrumpidas en función del Golpe Militar de 1964 y solamente se retomaron en 1978, en la obra organizada por Fábio Wanderley Reis, Os partidos e o regime, ${ }^{3}$ cuyos propósitos eran básicamente los de conocer el nivel de conciencia del electorado y su percepción sobre los partidos políticos permitidos en aquel periodo: la Alianza Nacional Renovadora (ARENA), que representaba el gobierno, y el Movimiento Democrático Brasileño (MDB), de oposición. Después de la redemocratización brasileña, iniciada en los años ochenta, los estudios acerca del comportamiento político municipal fueron escasos, restrictos a algunas regiones

1 Érica Anita Baptista Silva es periodista y Máster en Comunicación por la "Pontifícia Universidade Católica de Minas (Brasil).

Email: anitaerica@gmail.com

2 Paulo Victor Melo es sociólogo y estudiante del Máster en Ciencia Política en la "Universidade Federal de Minas Gerais". (Brasil).

Email: paulovictormelo@gmail.com

3 En la obra, los autores investigaron la lógica del proceso electoral teniendo como base los datos de una investigación por muestreo, realizada en las tres semanas anteriores a la elección municipal de 1976 en cuatro ciudades consideradas de mediano porte: Presidente Prudente (SP), Caxias do Sul (RS), Niterói (RJ) y Juiz de Fora (MG) - una vez que las elecciones para alcalde en las capitales estaban suspendidas-. 
del país y con metodologías apoyadas principalmente en datos electorales añadidos. Pocas propuestas académicas buscaron corroborar o aún contestar las "lógicas" del voto para el plano local. Las inferencias sobre la conducta del elector en los municipios han sido, por lo tanto, influenciadas por los resultados encontrados a lo largo de los años '70, pese a los cambios institucionales, económicos y sociales que tuvieron lugar en el país en las décadas siguientes.

Por ello, los organizadores de esta obra tenían como objetivo verificar si la conducta del elector, en el periodo post-redemocratización, seguía estando basada, principalmente, en unos estudios económicos y sociales, como previsto por la literatura de los años ' 70 , o si otras consecuencias se produjeron por este conjunto de cambios institucionales y económicos. En el proceso de redemocratización, ocurrieron transformaciones significativas, con la introducción de nuevas reglas relativas a las disputas, la posibilidad de coaliciones entre partidos, el derecho de los partidos a expresarse libremente y el significativo crecimiento de la agremiaciones partidarias, lo que resultó en el incremento de la competitividad del sistema partidario y la fragmentación política en las casas de representación, incluso en el plano local. Incontables otras modificaciones ocurrieron en el mismo perfil del electorado brasileño -que más escolarizado y más maduro se ha ido familiarizando con el proceso de participación electoral, con más acceso a las informaciones pertinentes-. Los electores pudieron elegir un candidato afiliado a un partido de izquierda para gobernar el país, una elección, en el plan federal, que puede haber generado efectos sobre los patrones de voto en los municipios. Además, a una "cultura parroquialista", aparentemente presente los años '70, en los pequeños municipios rurales -en los cuales los liderazgos políticos tienen más posibilidad de control e influencia-, se ha añadido una práctica más asociativa y participativa, que 
se esparció nacionalmente, generando actitudes más críticas en relación a los gobiernos y sus administradores. Vale subrayar aún que estas alteraciones políticas fueron concomitantes a nuevos patrones socioeconómicos. La contraposición urbano/rural fue atenuada, sobre todo por la popularización del acceso a los medios comunicacionales y por la simultaneidad de las informaciones, ofrecidas durante los periodos de campaña.

Teniendo como foco las elecciones municipales de 2008, el libro trata sobre el comportamiento de electores que definieron su voto bajo un contexto distinto. En función de estas nuevas configuraciones, ¿sería la conducta de los electores brasileños la misma? Para responder a esta cuestión, treinta y dos reconocidos expertos en el comportamiento electoral de prestigiosas instituciones universitarias brasileñas participantes y colaboradores del Grupo de Investigación "Opinión Pública, Marketing Político y Comportamiento Electoral" (Universidade Federal de Minas Gerais, Brasil), fueron invitados a debatir sobre teorías y métodos a lo largo de casi dos años. La dinámica electoral es analizada mediante diferentes teorías sobre el comportamiento político, incorporando hipótesis de las corrientes sociológicas, psicológicas, elección racional, además de las tesis más recientes sobre el votante intuitivo. Para descifrar las campañas y las decisiones de voto, los investigadores, de forma pionera, han utilizado un conjunto de datos cuantitativos y cualitativos, ${ }^{4}$ tales como las encuestas de opinión, entrevistas cualitativas, prensa, publicidad de los partidos, además de la información proporcionada por los organismos electorales de Brasil. Con toda esta evidencia se han llevado a cabo modelos econométricos y descriptivos,

Utilización de bases de datos de los institutos encuestadores: Datafolha, Ibope y Ipespe. 
que subsidian la interpretación de las elecciones municipales de 2008.

Los capítulos investigan la lógica del elector a partir de diferentes hipótesis, sacadas de los paradigmas micro y marco procesales, respetándose la autonomía teórica de cada autor, además de las diferentes corrientes explicativas. Los organizadores, con la intención de permitir que el lector pueda hacer comparaciones, diseñaron un recorrido estructural que tiene inicio con la contextualización de la nueva configuración del sistema político partidario del municipio, pasando por los impactos del desarrollo socioeconómico y mediático sobre las actitudes y el comportamiento de los electores, evaluando los vínculos psicológicos entre los electores y partidos políticos y considerando la incidencia de los efectos de las estrategias de campaña sobre las opiniones de los electores.

Los ensayos se centraron en las principales capitales de Brasil: São Paulo, Minas Gerais y Rio de Janeiro, en la región sureste; Porto Alegre, Curitiba y Florianópolis, en la región sur; Salvador, Recife y Fortaleza en el noreste; Belém y Manaus, en el norte, y Goiânia en la región del medio oeste. Todos estos casos conforman un mosaico detallado y sin precedentes de la decisión del voto en Brasil, lo que permite que se identifiquen similitudes y diferencias entre las capitales en las elecciones a la alcaldía, lo que se traduce en avance del conocimiento acerca de la política municipal.

Los casos analizados contemplaron capitales con características distintas en términos políticos y económicos, lo que permitió a los autores realizar algunas inferencias sobre las lógicas que orientan la elección del alcalde. Estas elecciones municipales de 2008 se realizaron bajo el signo del continuismo y de las asociaciones. Pero mantenidas igualmente estas condiciones para todas las capitales, se notó que el elector reaccionó de modo distinto en cada una de las disputas y no se encontró un mismo patrón de 
explicación para el voto. El ambiente de la disputa condicionó la decisión de modo diferente en cada una de las capitales. El comportamiento del elector parece revelar no solamente dimensiones ideológicas y normativas, sino también posiciones que reflejan los acuerdos y las estrategias que pueden ser establecidos entre los alcaldes y los gobiernos, combinados con elementos socioeconómicos, disposiciones políticas y estrategias de campaña.

En la literatura sobre el sistema federal de Brasil, ${ }^{5}$ el papel del poder ejecutivo municipal no ha sido suficientemente estudiado. En este sentido, el libro representa una contribución significativa, que investiga las motivaciones que llevan a la elección del candidato a la alcaldía. En Brasil se adopta el sistema proporcional con lista abierta, lo que genera unas estrategias electorales muy personalizadas. Por esta razón, los votantes brasileños, en general, responsabilizan al Jefe del Ejecutivo más que a los mismos partidos por los errores y aciertos político-administrativos. Por lo tanto, el desempeño de los alcaldes sirve como un atajo cognitivo de los votos, tanto al nivel local como al nivel estadual. Así, en un sistema político integrado como el brasileño, el gobierno de la ciudad puede convertirse en una importante base electoral para los partidos políticos. Como el municipio es la esfera más cercana a los votantes, los administradores de los municipios acumulan capital que puede ser transferido para las elecciones de sus candidatos para el estado o bien para el plano nacional, como diputados, senadores y gobernadores.

Con el crecimiento de su representación en el Congreso Nacional, los partidos tienen un mayor poder para negociar las políticas públicas y los presupuestos. La obtención de

El sistema de gobierno brasileño se compone por tres niveles de representación: nacional, estadual y municipal. Los tres niveles de gobierno cuentan con representación ejecutiva y legislativa. 
estos recursos garantiza que las demandas de las bases de los partidos sean atendidas, lo que resulta en un ciclo de influencia electoral en el que la lealtad de las bases locales sostiene el apoyo para el partido en las próximas elecciones en otros ámbitos. Este proceso puede ser corroborado si se analizan los resultados obtenidos para la Cámara de Diputados en las elecciones nacionales de 2010. Según el primer capítulo del libro, la conquista de los municipios puede traducirse en el aumento de la representación en el ámbito nacional.

El punto destacado como una marca de las elecciones intermedias de 2008 fue la retórica de las campañas que no añadió cuestiones relativas a la crisis económica, aunque el mundo estuviera en medio a una de las mayores crisis que se haya registrado. En situaciones de crisis, es común percatarse de un sentimiento de pesimismo en la opinión pública, además de restricciones sobre el presupuesto de los municipios. Sin embargo, lo que se vio en las elecciones de 2008 fue diferente. Los candidatos hicieron uso de los números positivos de la economía brasileña y de la sensación de bienestar, lo que se reflejó en los resultados electorales. La llamada al voto retrospectivo permitió que 19 de los 20 candidatos a la reelección siguieran en el gobierno de las capitales. Por lo tanto, el elevado número de alcaldes reelegidos fue otro aspecto que caracterizó las elecciones de 2008.

Mientras la economía mundial no fue un tema recurrente, lo que se encontró fue la llamada personalista y de la asociación con el Gobierno Federal. Esta estrategia se debió a la alta aprobación del entonces presidente Luiz Inácio Lula da Silva, del Partido de los Trabajadores (PT). Una vez que se mostraban alineados con el Gobierno Federal, muchos de los candidatos a alcalde buscaban asociar su imagen al presidente Lula da Silva como garantía de buen gobierno en el futuro. 
Las coaliciones políticas también fueron evidentes en esta elección. A pesar de las ideologías o programas, los partidos que se habían enfrentado históricamente en las disputas electorales nacionales firmaron acuerdos y apoyaron a los mismos candidatos, incluso a través de coaliciones informales, en contradicción con las posiciones de sus respectivos Directorios Nacionales. Por lo tanto, la búsqueda por la transferencia de prestigio del Gobernador o del Presidente para el Alcalde fue una apuesta realizada por las élites políticas durante el proceso de reclutamiento de los candidatos. Se puede ver en una de las capitales que el alcalde y el gobernador de partidos opositores se unieron por un candidato, basándose principalmente en sus aprobaciones populares, lo que pone de relieve las raíces personalistas de la cultura brasileña.

Sin embargo, a pesar de encontrar personalismo y coaliciones entre los partidos concurrentes, no se puede decir, basándose en los estudios de caso presentados, que los partidos hayan perdido su importancia. Al menos en las elecciones intermedias, se nota que los partidos pueden crear vínculos psicológicos con los votantes, lo que se puede observar en algunas de las capitales. Así, aunque las preferencias de partido y las ideologías no son las únicas explicaciones para la decisión de los votos en 2008, no se los puede desconsiderar en nuevos estudios por venir.

La comunicación política ha sido objeto de análisis en cada capítulo, lo que diferencia esta publicación de otras. La mayor parte de los estudios brasileños se concentra en el comportamiento del elector y sus razones de voto o exclusivamente en la comunicación política. La combinación entre estas dos dimensiones de análisis no es corriente en los estudios. Al analizar la relación entre la elección de los candidatos y las campañas, los autores muestran la importancia de las variables a corto plazo en la decisión del voto. A pesar de la aparición de nuevas tecnologías, 
las pruebas mostraron que la televisión, que transmite los programas electorales obligatorios y spots, sigue siendo el principal vehículo utilizado en las campañas a la alcaldía, además de ser una fuente importante de información para los votantes. Como ya se conoce por la literatura nacional y lo confirman los autores de esta obra, se pudo observar que una mayor disponibilidad financiera y más tiempo de publicidad en radio y televisión permiten que los candidatos incrementen sus apoyos y alcancen la victoria.

El proceso de convencimiento de los votantes se refiere tanto a la construcción de una imagen positiva como a la destrucción de los oponentes. En 2008, además de las formas tradicionales de persuasión y movilización, los ataques, especialmente la través de las redes sociales, fueron más frecuentes. Ello indica la necesidad de nuevos estudios para examinar la campaña negativa, una técnica de uso frecuente en las elecciones que tiene lugar en varios países.

Brasil no es un país políticamente homogéneo. La existencia de más de cinco mil municipios implica particularidades que limitan las conclusiones generales sobre el comportamiento electoral. Sin embargo, basándose en los casos estudiados, los organizadores descubren algunos patrones en los cuales las diputas se han desarrollado: elecciones con los debates en que los temas locales eran importantes; elecciones federalizadas, donde la política nacional tiene una fuerte interferencia en la articulación de las élites y por último, la importancia vital del Gobernador para el éxito del alcalde. Además, los organizadores presentan algunos hallazgos sobre la decisión del voto para alcalde, en el que los factores estructurales, tales como la articulación de las élites, se combinan con las disposiciones políticas de los votantes y con unos elementos coyunturales, tales como la evaluación retrospectiva y las campañas electorales. Todas estas variables forman un complejo panorama explicativo. 
El libro no pretende finalizar los debates sobre el voto en los municipios. Tampoco se limita a la definición de métodos de análisis o la adopción de una escuela teórica única. Subrayamos que el libro no presenta análisis sobre los procesos electorales de municipios más pequeños. Se verifica, en ese sentido, que la literatura brasileña todavía tiene algunas carencias en los estudios que tratan las elecciones municipales en pequeñas ciudades. A pesar de la inclusión de investigaciones académicas cuantitativas y cualitativas en muchos capítulos, parte de los datos analizados se basan en surveys comerciales, lo que limita la profundización de algunas hipótesis, que podrían ser probadas.

Aunque no sea posible diseñar características específicas sobre el electorado brasileño teniendo como base el estudio de 12 capitales y una única elección, se pueden inferir algunas conclusiones teóricas relevantes. Primero la de que el elector hizo uso del voto retrospectivo, lo que permitió que la mayoría de los alcaldes fuera reelecta. A pesar de que el voto retrospectivo haya sido considerado de mayor relevancia en las capitales estudiadas, el elector opera en cada ciudad con una lógica propia y se sirve de diferentes informaciones para respaldar sus decisiones, lo que resulta en lógicas internas de cada ciudad, ya que la dinámica de la decisión de voto es diferente para los niveles locales, estaduales y municipales. Otro hallazgo es que las campañas electorales mostraron ser predictoras del voto, sobre todo en función de la importante volatilidad y del reducido vínculo psicológico entre electores y partidos. Se nota que las campañas pueden activar las preferencias y disposiciones previas y son uno de los principales instrumentos para la oferta de informaciones utilizadas por los electores para orientar su decisión. En este sentido, las pocas informaciones disponibles permiten al elector usarlas para la toma decisiones más racionales -en consonancia con sus perspectivas-. 
Con base en los casos presentados, se presentan algunas consecuencias con relación a la conducta del elector. Contraponiéndose al "localismo", las ideologías también estuvieron presentes en algunas capitales. Aunque el elector no conozca las distinciones sustantivas entre derechas e izquierdas, se observa que, en algunas ciudades, como São Paulo, Belo Horizonte y Florianópolis, los bloques de poder partidarios identificados con algunas de estas políticas permanecieron controlando el ayuntamiento por mucho tiempo, lo que les permitió crear vínculos con el elector. En estas situaciones, las disposiciones políticas ideológicas pueden afectar a la elección del alcalde, aunque se considere además los atributos funcionales y personales de los candidatos.

Se concluye que temas importantes surgieron en los capítulos, dando lugar a nuevas investigaciones con el fin de subsanar las principales deficiencias en los estudios electorales, tales como: el papel de los medios de comunicación y las campañas en las disputas políticas; la necesidad de estudios comparativos entre la realidad nacional y latinoamericana, y la escasa presencia de teorías interdisciplinarias para la interpretación del voto, con la inclusión de referencias del área de comunicación, psicología, antropología y neuropolítica. 